\title{
Protective effects of flavonoids from corn silk on oxidative stress induced by exhaustive exercise in mice
}

\author{
Qing-lan $\mathrm{Hu}^{1 \star}$ and Zhi-hong Deng ${ }^{2}$
}

\author{
${ }^{1}$ Kunming University of Science and Technology, Kunming, Yunnan Province, 650224, People's Republic of China. \\ ${ }^{2}$ Kunming University, Kunming, Yunnan Province, 650214, People's Republic of China. \\ Accepted 17 March, 2011
}

\begin{abstract}
The present study aims at exploring the effects of flavonoids from corn silk (FCS) on oxidative stress induced by exhaustive exercise in mice. Sixty mice were randomized into 3 groups: Low-dose FCS treatment group (LFG), high-dose FCS treatment group (HFG) and control group (CG). The mice were treated with FCS (100 and $400 \mathrm{mg} / \mathrm{kg}$ ) or placebo (distilled water) by daily oral gavage for 28 days. After the last treatment, animals were submitted to treadmill for exhaustion and running time, malondialdehyde (MDA), superoxide dismutase (SOD) and glutathione peroxidase (GPX) levels were measured. The results suggested that FCS could elevate the exercise tolerance of mice, and provide protection against oxidative stress induced by exhaustive exercise in mice, by inhibiting lipid per-oxidation and increasing anti-oxidant enzymes levels.
\end{abstract}

Key words: Flavonoids from corn silk, oxidative stress, exhaustive exercise, mice

\section{INTRODUCTION}

Corn silk (also known as maize silk) is made up of the stigmas and styles of the maize plant belonging to the grass (Gramineae) family (Ren et al., 2009), and it has been used for thousands of years as a folk medicine in many parts of the world for the treatment of edema as well as for cystitis, gout, kidney stones, nephritis, diabetes mellitus and prostatitis (Velazquez et al., 2005; Li and Yu, 2009; Hu et al., 2010). It has been found that corn silk is an excellent source of many bioactive compounds such as flavonoids, saponin, alkaloids, tannins, chlorogenic acid, phytosterols, allantoin, vitamin $\mathrm{E}$ and $\mathrm{K}$ (Bushman, 2002). To date, several flavonoids such as maysin, apigmaysin, 3-methoxymaysine, ax-4-OHmaysin, etc, have been isolated and identified from corn silk (Snook et al., 1995; Ren et al., 2009; Hu et al., 2010). Flavonoids from corn silk (FCS) have been investigated and confirmed to possess various pharmacological activities such as antihypertensive, anti-infectious, anti-oxidative and anti-diabetic (Li and Yu, 2009; Liu et al., 2011).

Radicals are molecules or fragments of molecules that possess an unpaired electron in their outer orbital. As a

*Corresponding author. E-mail: hql2036@hotmail.com or hql2036@qq.com. Tel: +86-13708430750 result of this molecular instability, radicals are highly reactive and can promote damaging oxidation reactions with cellular proteins, lipids or DNA, leading to oxidative stress and impaired cellular function (Powers et al., 2004). The well-documented benefits of regular physical exercise include reduced risk of cardiovascular disease, cancer, osteoporosis and diabetes (Leeuwenburgh and Heinecke, 2001). However, muscular exercise results in increased production of radicals and other reactive oxygen species (ROS). During the last 20 years, much evidence indicated that radical generation is enhanced during strenuous exercise (Lawler et al., 1994; O'Neill et al., 1996; Vesovic et al., 2002; Powers et al., 2004; Lekhi I et al., 2007). To combat the deleterious effects of radicals and ROS, the body has some complex internal protective mechanisms like enzymatic defenses, which include primary antioxidative enzymes like super oxide dismutase (SOD), catalase, glutathione peroxidase (GPX) and nonenzymatic defenses like vitamin $C$, vitamin $E$, ubiquinol co-enzyme Q-10 and reduced glutathione. During exercise, the pro-oxidant/antioxidant balance shifts in favor of the former, with the rate of radical and ROS production exceeding their rate of removal by the antioxidant defense mechanisms (Lekhi et al., 2007; Gupta et al., 2009).

In recent studies, FCS has been shown to be a potent 
Table 1. Composition of experimental diets ( $\mathrm{g} / 100 \mathrm{~g}$ diet).

\begin{tabular}{lc}
\hline \multicolumn{1}{c}{ Ingredient } & Normal diet \\
\hline Choline bitartrate & 0.2 \\
DL-methione & 0.3 \\
Vitamin mixture & 1.0 \\
Mineral mixture & 3.5 \\
Cellulose & 5.0 \\
Sucrose & 50.0 \\
Corn starch & 15.0 \\
Casein & 20.0 \\
Bean oil & 5.0 \\
Carbohydrate $(\mathrm{kcal} / 100 \mathrm{~g})$ & 260.0 \\
Protein $(\mathrm{kcal} / 100 \mathrm{~g})$ & 85.0 \\
Fat $(\mathrm{kcal} / 100 \mathrm{~g})$ & 45.0 \\
Total calories $(\mathrm{kcal} / 100 \mathrm{~g})$ & 390.0 \\
\hline
\end{tabular}

scavenger of hydroxyl and peroxyl radicals (Ren et al., 2005; Ebrahimzadeh et al., 2008; Hu et al., 2009). Also, it has reported that FCS had anti-fatigue activity (Hu et al., 2010). The present study aimed to examine the effect of FCS on oxidative stress induced by exhaustive exercise in mice.

\section{MATERIALS AND METHODS}

\section{Plant materials}

Corn silk (Zea mays L. cv Longdan38) was collected from the horticultural center of Kunming University of Science and Technology (Kunming, China) and identified by Professor Li MC, plant taxonomist, Department of Biology, Yunnan Normal University (Kunming, China). Fresh corn silk was washed with distilled water, and dried for $24 \mathrm{~h}$ by using a hot air oven at $60^{\circ} \mathrm{C}$ and powdered using a grinder, and then stored in a drying cabinet before the experiment.

\section{Preparation of flavonoids from corn silk}

The dried corn silk powder $(10 \mathrm{~g})$ was subjected to hot continuous extraction in Erlenmeyer flask with ethanol (ethanol concentration $60 \%$, ratio of solvent to raw material 10 ), while the temperature of the water bath was $70^{\circ} \mathrm{C}$. After $1.5 \mathrm{~h}$, the extract was filtered through the filter. The obtained filtrate was evaporated by using a rotary evaporator to get the crude flavonoids from corn silk (FCS) (Li and $\mathrm{Yu}, 2009$ ). AB-8 macroporous resins (Cangzhou Bon Chemical Co., Hebei, China) was used for obtaining purified FCS. The resins were pretreated and activated according to the manufacturer's recommendation. FCS was adsorbed onto the column: processing volume was $4 \mathrm{BV}$; flow rate was $2 \mathrm{BV} / \mathrm{h}$; temperature was $25^{\circ} \mathrm{C}$. The adsorbed material was eluted: elution solvent ethanol-water $(90 \%$, $\mathrm{v} / \mathrm{v}$ ) solution was $4 \mathrm{BV}$; flow rate was $1.0 \mathrm{BV} / \mathrm{h}$. The eluent was concentrated on a rotary evaporator under reduced pressure at $60^{\circ} \mathrm{C}$ and the resulting concentrate was lyophilized to get purified FCS (Hu et al., 2010).

\section{Experimental animals and diet}

Kunming mice were purchased from the Center of Laboratory
Animal, Kunming University of Science and Technology (Kunming, China). The male mice weighed between 18 and $22 \mathrm{~g}$ at the time of experiment. They were housed in standard cages of $20 \times 30 \times 15 \mathrm{~cm}$ (5 mice/cage) under controlled conditions of temperature $\left(23 \pm 1^{\circ} \mathrm{C}\right)$, humidity $(50 \pm 5 \%)$ and lighting (lights on from 08:00 to 20:00). They were provided a normal diet and water ad libitum. The composition of the experimental diet is shown in Table 1. Experiments were performed in accordance with institutional and governmental guidelines after approval of the Animal Experimentation Ethics Committee, Kunming University of Science and Technology.

\section{Experimental protocol}

Sixty mice were randomized into 3 groups equally based on body weight after one week adoption: low-dose FCS treatment group (LFG), high-dose FCS treatment group (HFG) and control group (CG). The mice were treated with FCS (100 and $400 \mathrm{mg} / \mathrm{kg}$ ) or placebo (distilled water) by daily oral gavage for 28 days. Volume of solution to gavage mice is $3 \mathrm{ml}$, and the dose of 100 and $400 \mathrm{mg} / \mathrm{kg}$ was chosen based on estimates from a previous study. The FCS solution used in treatment groups was prepared through dissolving FCS in distilled water.

Before the exhaustive exercise, all mice were acclimatized to the treadmill (TSE Treadmill System, QiChi Instrument, Shanghai, China) during a 3 day period with 5 min of rest and 5 min of running at $10 \mathrm{~m} / \mathrm{min}$ and $0^{\circ}$ inclination each day (Fäldt et al., 2004; Fernandez et al., 2008; Shan et al., 2010). After 28 days, animals were submitted to treadmill running, a kind of exercise in which intensity and duration are easily manipulated and quantified in contrast to voluntary wheel or swimming exercises (Rosa et al., 2008). The test started with a $10^{\circ}$ incline and $10 \mathrm{~m} / \mathrm{min}$ belt speed. The speed was increased to $14 \mathrm{~m} / \mathrm{min}$ after $10 \mathrm{~min}$ and to $18 \mathrm{~m} / \mathrm{min}$ after another $5 \mathrm{~min}$. The mice continued to run at $18 \mathrm{~m} / \mathrm{min}$ until exhaustion. Exhaustion is define as the inability to continue regular treadmill running despite the stimulus of repeated tapping on the back of the mouse (Fäldt et al., 2004). The running time of mice were recorded.

\section{Biochemical analysis}

Immediately after exhaustive exercise, all the mice were anesthetized to death with high concentration ether in an acrylic plastic immobilizer. Skeletal muscle tissue was carefully removed, rinsed in ice-cold normal saline, blotted dry, and stored at $-80^{\circ} \mathrm{C}$ for malondialdehyde (MDA) and anti-oxidant enzymes (superoxide dismutase and glutathione peroxidase) analysis.

MDA, super oxide dismutase (SOD) and glutathione peroxidase (GPX) were tested according to the recommended procedures provided by the kits purchased from Nanjing Jiancheng Bioengineering Institute (Jiangsu, China).

\section{Statistical analysis}

All data were expressed as means \pm SD of three replications and subjected to one-way analysis of variance followed by t-test for multiple comparisons. For a single comparison, the significance of differences between means was determined by Student's t-test. A level of $p<0.05$ was considered statistically significant. Data were analyzed using the statistical package "SPSS 12.0 for Windows".

\section{RESULTS AND DISCUSSION}

\section{Effect of FCS on running times of mice}

As shown in Figure 1, the running times of mice in treat- 


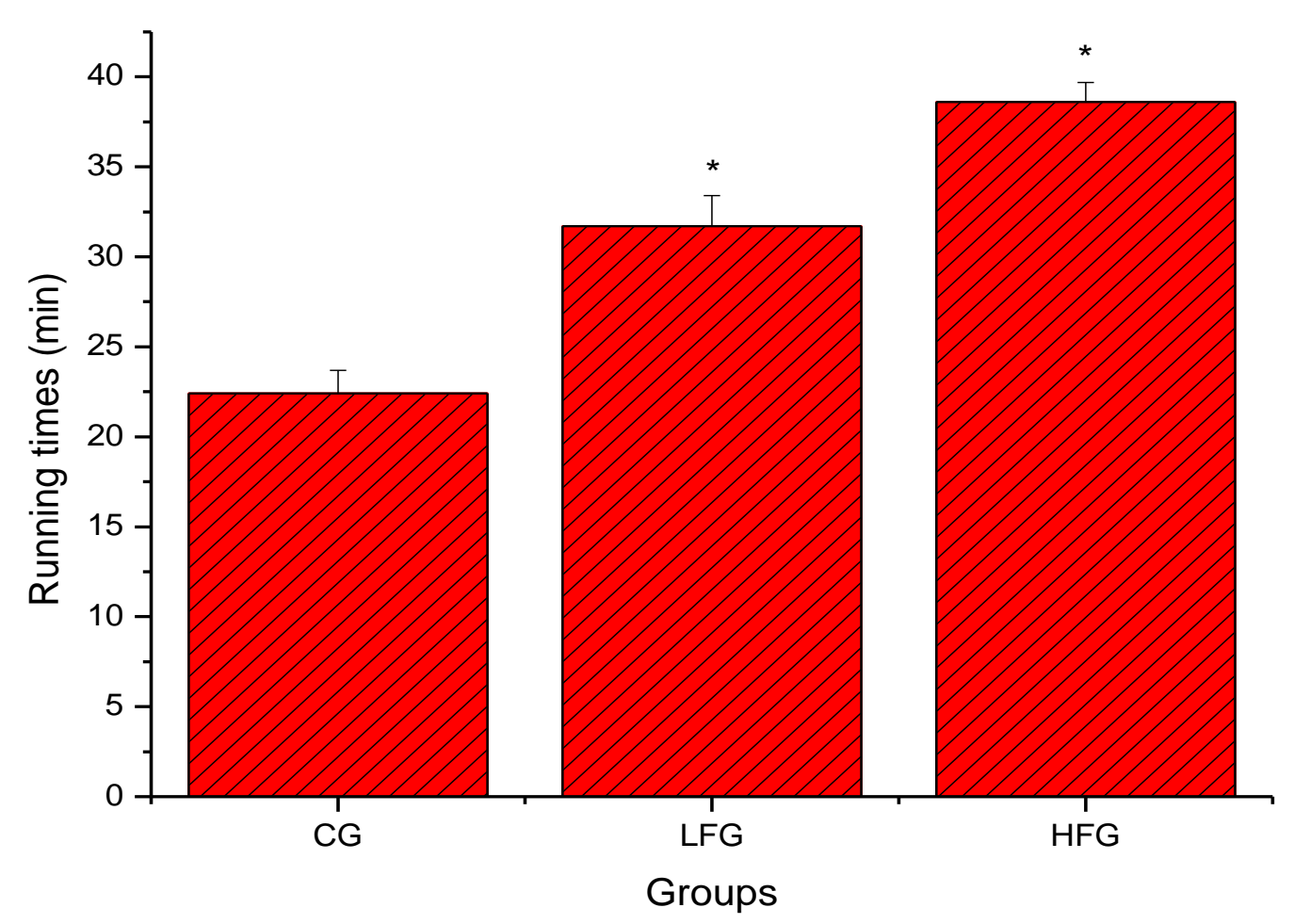

Figure 1. Effect of FCS on running times of mice. CG, Control group; LFG, low-dose FCS treatment group; HFG, high-dose FCS treatment group. Results are presented as the mean \pm S.D. $(n=20)$. ${ }^{*} p<$ 0.05 as compared with the control group.

ment groups (LFG and HFG) were significantly prolonged when compared to the control group $(p<0.05)$, and increased by 41.52 and $72.32 \%$, respectively. The results showed that FCS could elevate the exercise tolerance of mice.

\section{Effect of FCS on MDA levels of mice}

Oxidative stress induced by exhaustive exercise can significantly elevate markers of tissue per-oxidative damage because physical exercise promotes the production of ROS due to a substantial increase in oxygen consumption (Pfeiffer et al., 1999; Chen et al., 2002). The MDA, a metabolite of phospholipid peroxidation, is a popular index of first condition on living body oxidative damage (Lu et al., 2006). As shown in Figure 2, MDA levels in skeletal muscle of mice in treatment groups (LFG and HFG) were significantly decreased when compared to the control group $(p<0.05)$, and decreased by 26.46 and $37.91 \%$, respectively. The results showed that FCS protected skeletal muscles from ROS-mediated oxidative damage during exhaustive exercise.

\section{Effect of FCS on anti-oxidant enzymes levels of mice}

SOD and GPX are regarded as the first line of the antioxidant defense system against oxygen free radicals generated during strenuous exercise (Oh-ishi et al., 1997). The increase in anti-oxidant enzymes in muscle would indicate an up-regulation of the defense mechanism to try to cope with an enhanced production of superoxide anion radicals. This in turn might help to down-regulate the production of lipid peroxides or oxidative stress (Lee et al., 2009), although controversy still remains. As shown in Table 2, SOD and GPX levels in skeletal muscle of mice in treatment groups (LFG and HFG) were significantly increased when compared to the control group $(p<0.05)$. Many studies showed FCS have antioxidant properties in vitro, which can be used potentially as a ready accessible and valuable bioactive source of natural antioxidants (Maksimović and Kovacević, 2003; Maksimović et al., 2005). It is also reported that antioxidant nutrient status and exercise training have an interactive effect on oxidative stress and antioxidant enzyme activities (Choi and Cho, 2009). The results indicated that FCS was able to up-regulate antioxidant enzymes activity to protect against oxidative stress induced by acute exercise. This is probably due to the per se antioxidant activity of FCS.

\section{Conclusions}

Oxidative stress induced by exhaustive exercise is linked with increased lipid per-oxidation. Administration of flavo- 


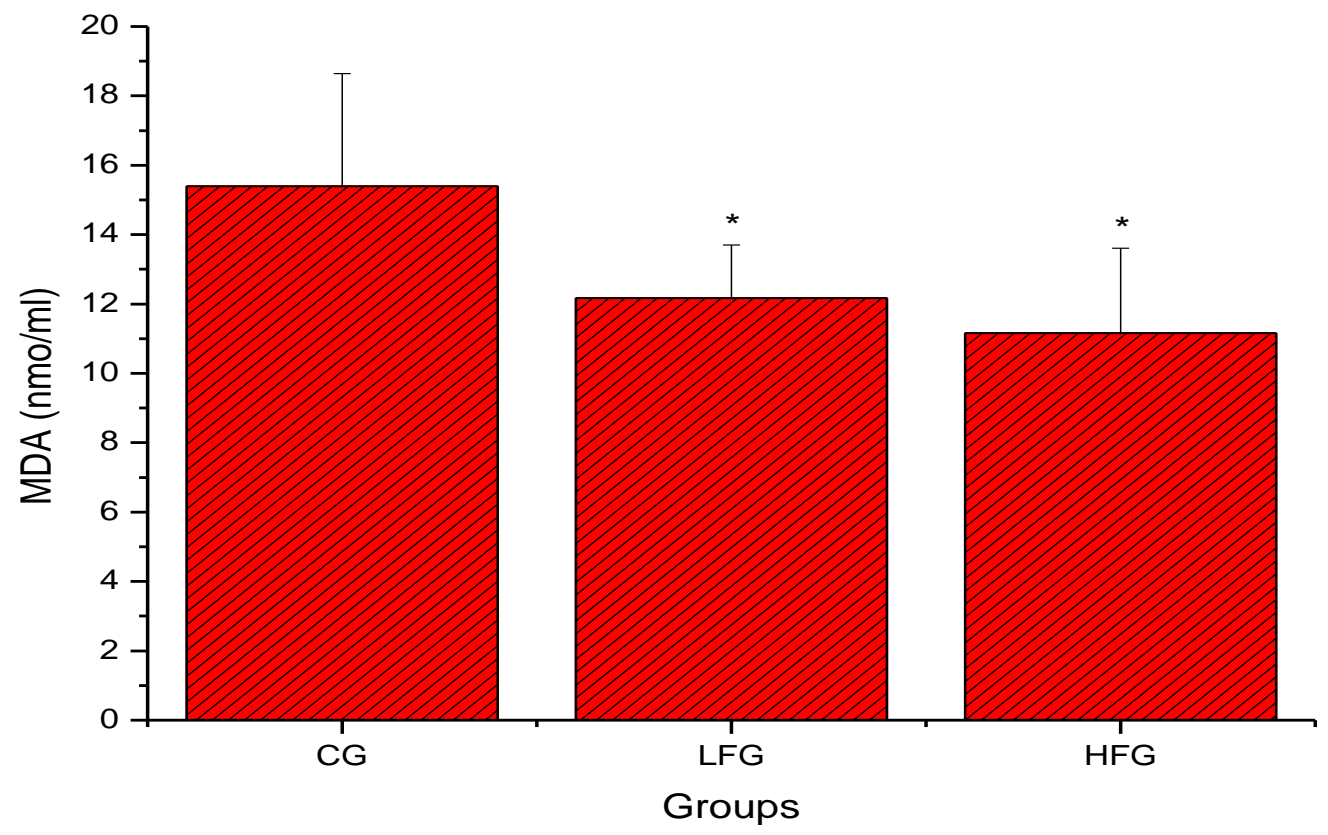

Figure 2. Effect of FCS on malondialdehyde (MDA) levels of mice skeletal muscle. CG, Control group; LFG, low-dose FCS treatment group; HFG, high-dose FCS treatment group. Results are presented as the mean \pm S.D. $(n=20)$. ${ }^{*} p<0.05$ as compared with the control group.

Table 2. Effect of FCS on anti-oxidant enzymes levels of mice skeletal muscle.

\begin{tabular}{lcc}
\hline \multicolumn{1}{c}{ Group } & SOD (U/mg) & GPX(U/ml) \\
\hline CG & $10.79 \pm 0.51$ & $41.17 \pm 6.24$ \\
LFG & $13.24 \pm 0.68^{*}$ & $55.38 \pm 4.49^{*}$ \\
HFG & $14.02 \pm 0.74^{*}$ & $64.21 \pm 5.27^{*}$ \\
\hline
\end{tabular}

CG, Control group; LFG, low-dose FCS treatment group; HFG, high-dose FCS treatment group. Results are presented as the mean \pm S.D. $(n=20)$. ${ }^{*} p<0.05$ as compared with the control group. SOD, superoxide dismutase GPX, glutathione peroxidase

noids from corn silk provides protection against oxidative stress induced by exhaustive exercise in mice, by inhibiting lipid per-oxidation and increasing anti-oxidant enzymes levels.

\section{REFERENCES}

Bushman BS (2002). The genetic basis of chlorogenic acid synthesis in maize. PhD dissertation, University of Missouri-Columbia, Missouri, United States.

Chen CY, Holtzman GI, Bakhit RM (2002). High-Genistin Isoflavone Supplementation Modulated Erythrocyte Antioxidant Enzymes and Increased Running Endurance in Rats Undergoing One Session of Exhausting Exercise - A pilot study. Pak. J. Nutr. 1 (1): 1-7.

Choi EY, Cho YO (2009). Effect of vitamin B(6) deficiency on antioxidative status in rats with exercise-induced oxidative stress. Nutr. Res. Pract. 3(3): 208-211.

Ebrahimzadeh MA, Pourmorad F, Hafezi S (2008). Antioxidant Activities of Iranian Corn Silk. Turk. J. Biol. 32: 43-49.

Fäldt J, Wernstedt I, Fitzgerald SM, Wallenius K, Bergström G, Jansson
JO (2004). Reduced exercise endurance in interleukin-6-deficient mice. Endocrinology, 145(6): 2680-2686.

Fernandez C, Hansson O, Nevsten P, Holm C, Klint C (2008). Hormone-sensitive lipase is necessary for normal mobilization of lipids during submaximal exercise. Am. J. Physiol. Endocrinol. Metab. 295(1): E179-186.

Gupta C, Gupta PH, Singh B (2009). Effect of Vitamin Supplementation on Exercise Induced Oxidative Stress in Trained Elite Indian Cyclists. Am. J. Biomed. Sci. 1: 166-170.

Hu DH, Gao YH, Chen XS, Qiu ZD (2009). Quantum chemistry studies on molecular structure and character of the flavonoids in herbs of corn silk and their anti-oxidation activity. J. Northeast Normal Univ. 4: 63-67.

Hu QL, Zhang LJ, Ding YJ, Li FL (2010). Purification and anti-fatigue activity of flavonoids from corn silk. Int. J. Physical Sci. 5(4): 321-326.

Lawler JM, Powers SK, Van Dijk H, Visser T, Kordus MJ, Ji LL (1994). Metabolic and antioxidant enzyme activities in the diaphragm: effects of acute exercise. Respir. Physiol. 96(2-3): 139-149.

Lee SP, Mar GY, Ng LT (2009). Effects of tocotrienol-rich fraction on exercise endurance capacity and oxidative stress in forced swimming rats. Eur. J. Appl. Physiol. 107(5):587-595.

Leeuwenburgh C, Heinecke JW (2001). Oxidative stress and antioxidants in exercise. Curr. Med. Chem. 8(7): 829-838.

Lekhi C, Gupta PH, Singh B (2007). Influence of exercise on oxidant stress products in elite Indian cyclists. Br. J. Sports Med. 41: 691-693.

Li FL, Yu L (2009). Flavonoids extraction from maize silk and its function on blood sugar control. China Food Additives, 94: 121- 124.

Liu J, Wang CN, Wang ZZ, Zhang C, Lu S, Liu JB (2011). The antioxidant and free-radical scavenging activities of extract and fractions from corn silk (Zea mays L.) and related flavone glycosides. 126: 261-269.

Lu HK, Hsieh CC, Hsu JJ, Yang YK, Chou HN (2006). Preventive effects of Spirulina platensis on skeletal muscle damage under exercise-induced oxidative stress. Eur. J. Appl. Physiol. 98(2): 220-226.

Maksimović Z, Malencić D, Kovacević N (2005). Polyphenol contents and antioxidant activity of Maydis stigma extracts. Bioresour. Technol. 96(8): 873-877.

Maksimović ZA, Kovacević N (2003). Preliminary assay on the 
antioxidative activity of Maydis stigma extracts. Fitoterapia, 74(1-2): 144-147.

O'Neill CA, Stebbins CL, Bonigut S, Halliwell B,Longhurst JC (1996). Production of hydroxyl radicals in contracting skeletal muscle of cats. J. Appl. Physiol. 81: 1197-1206.

Oh-ishi S, Kizaki T, Ookawara T, Sakurai T, Izawa T, Nagata N, Ohno H (1997). Endurance training improves the resistance of rat diaphragm to exercise-induced oxidative stress. Am. J. Respir. Crit. Care Med. 156(5): 1579-1585.

Pfeiffer JM, Askew EW, Roberts DE, Wood SM, Benson JE, Johnson SC Freedman MS (1999). Effect of antioxidant supplementation on urine and blood markers of oxidative stress during extended moderate-altitude training. Wilderness Environ. Med. 10(2): 66-74.

Powers SK, DeRuisseau KC, Quindry J, Hamilton KL (2004). Dietary antioxidants and exercise. J. Sports Sci. 22(1): 81-94.

Ren SC, Ding XL, Shi XH (2005). Antioxidant activiy of ax-5"-methane-3'-methoxymaysin and ax-4"-oh-3'-methoxymaysin from corn silk. J. Zhengzhou Institute Technol. 6: 16-20.

Ren SC, Liu ZL, Ding XL (2009). Isolation and identification of two novel flavone glycosides from corn silk (Stigma maydis). J. Med. Plants Res. 3(12): 1009-1015.
Rosa EF, Freymüller E, Ihara SS, Aboulafia J, Nouailhetas VL (2008). Damaging effects of intense repetitive treadmill running on murine intestinal musculature. J. Appl. Physiol. 104(5): 1410-1417.

Shan $Y, Y e X H$, Xin H (2010). Effect of the grape seed proanthocyanidin extract on the free radical and energy metabolism indicators during the movement. Sci. Res. Essays, 5: 148-153.

Snook ME, Widstrom NW, Wiseman BR, Byrne PF, Harwood JS, Costello CE (1995). New C-4_-hydroxy derivatives of maysin and 3 -methoxymaysin isolation from corn silks (Zea mays). J. Agric. Food Chem. 43: 2740-2745.

Velazquez DVO, Xavier HS, Batista JEM, de Casro- Chaves C (2005). Zeamays L. Extracts modify glomerular function and potassium urinary excretion in conscious rats. Phytomedicine Hytomedicine, 12: 363- 369.

Vesovic D, Borjanovic S, Markovic S, Vidakovic A (2002). Strenuous exercise and action of antioxidant enzymes. Med. Lav. 93(6): 540-550. 